\title{
Assessment of Key Environmental Factors Influencing the Sedimentation and Aggregation Behavior of Zinc Oxide Nanoparticles in Aquatic Environment
}

\author{
Rizwan Khan (D), Muhammad Ali Inam ${ }^{(D)}$, Saba Zam Zam, Du Ri Park and Ick Tae Yeom * \\ Graduate School of Water Resources, Sungkyunkwan University (SKKU) 2066, Suwon 16419, Korea; \\ rizwankhan@skku.edu (R.K.); aliinam@skku.edu (M.A.I.); sabazamzam@skku.edu (S.Z.Z.); \\ enfl8709@skku.edu (D.R.P.) \\ * Correspondence: yeom@skku.edu; Tel.: +82-31-299-6699
}

Received: 1 May 2018; Accepted: 15 May 2018; Published: 18 May 2018

\begin{abstract}
Zinc oxide nanoparticles ( $\mathrm{ZnO} \mathrm{NPs}$ ) are among the most widely used engineered nanoparticles (ENPs) in various commercial sectors to achieve both social and economic benefits. The post-use release of these NPs to the environment is inevitable, and may pose threat to the human and eco-system. In the present study, we investigated the influence of single and multiple environmental factors on sedimentation behavior of $\mathrm{ZnO}$ NPs. The fractional-factorial method based on Taguchi orthogonal array $(\mathrm{OA}) \mathrm{L}_{27}\left(3^{13}\right)$ design matrix was used for systematic investigation on the contribution and significance of multiple factors and their interactions. The result of single-factor showed that the $\mathrm{ZnO}$ NPs were unstable at or near $\mathrm{pH}_{\mathrm{zpc}}$, with high electrolyte concentration; however, the adsorption of natural organic matter (NOM) i.e., humic acid, salicylic acid, and citric acid reverses the surface charge and enhanced NP stability. The Fourier transform infrared (FT-IR) analysis confirms the organic capping ligands on the NP surface. Moreover, the matrix result of analysis of variance (ANOVA) showed that electrolyte concentration and type, and NOM concentration were the most significant factors $(p<0.001)$ in promoting and influencing aggregation, while the interaction between the factors was also found insignificant. In addition, the result of aggregation kinetics and environmental water samples indicated that the mobility of ENPs may vary substantially in an environment with complex and heterogeneous matrices. This study may contribute to better understanding and prediction of the sedimentation behavior and fate of ZnO NPs in aqueous environments, to facilitate their sustainable use in products and process.
\end{abstract}

Keywords: aggregation kinetics; environmental factors; sedimentation; stability; Zinc oxide nanoparticles

\section{Introduction}

Engineered nanoparticles (ENPs) are being utilized in numerous modern fields including medical, agricultural, consumer products and industrial process because of their unique structural properties. It is estimated that these ENPs are part of more than 1200 commercial products. Among them, zinc oxide nanoparticles (ZnO NPs) are an extensively used nanomaterial in the field of cosmetic products, sunscreen formulas, catalytic activities, marine antifouling paints, packaging, and agricultural biocide due to their novel physicochemical properties [1,2]. The annual global production of ZnO NPs was estimated to be 570 tons/year in 2010, which is anticipated to be $1600-58,000$ tons/year by $2020[1,3]$. However, the broad applications and production have given rise to concerns regarding its environmental release from point and non-point sources, which may increase the bioavailability and NPs toxicity to a wide range of organisms in the aquatic environment [4]. Therefore, the fate, mobility and exposure risk of ZnO NPs to human as well as species present in the aquatic environment are of particular concern. 
Previous studies have shown that ENPs can enter into the human body directly or through bioaccumulation and exhibit some toxicity, such as inflammatory response, and cell membrane leakage $[4,5]$. Similar hazardous effects on other aquatic biota including plants, mammalians, sea urchin and earthworms have also been reported [6,7]. The tiny size of NPs may cause significant variation in the sedimentation and aggregation kinetics under various solution matrices [8]. Moreover, they are considered stable in suspension and high capability to convey toxic substance, while large size NPs have a tendency to aggregate which results in enhanced sedimentation [9]. Additionally, substantial inhibition effect of ZnO NPs was found on nitrogen and phosphorus removal activities in activated sludge or wastewater biofilms due to the release of zinc ion $\left(\mathrm{Zn}^{2+}\right)$ [8]. In fact, the toxicity of these NPs is mostly attributed to surface properties, size, solubility, and various environmental factors of the aqueous solution $[10,11]$. Once discharged in the aquatic environment, the NPs may transform into different forms i.e., either aggregate and dissolve or redistribute by means of sedimentation [12]. Consequently, such behavior will affect their fate and toxicity in the overall system.

A number of studies [13-17] have shown that the sedimentation of NPs depends on various environmental factors mainly originated from water chemistry such as $\mathrm{pH}$, ionic strength (IS), temperature and natural organic matter (NOM) type and content. It has been demonstrated that the surface potential and stability of ZnO NPs are highly reliant on the suspension $\mathrm{pH}$, which influences through protonation/deprotonation of hydroxyl groups [13]. Similarly, the effects of various electrolytes i.e., monovalent $\left(\mathrm{Na}^{+}, \mathrm{K}^{+}\right.$, etc. $)$and divalent $\left(\mathrm{Ca}^{2+}, \mathrm{Mg}^{2+}\right.$ etc.) cations, have been reported $[14,15]$. The divalent cations efficiently compress the electrical double-layer (EDL) of NPs and consequently enhance the aggregation. In addition, the formation of zinc complexes with valence electrolytes also reduced the release of $\mathrm{Zn}^{2+}[16,17]$. Some researchers have shown that changes in the water temperature may exert an effect on the solubility of NPs and may alter also their physicochemical interactions [18].

The stabilizing effect of NOM such as humic acid, citric acid etc. on NPs in the aquatic system has been reported in the literature $[17,19]$. It has been shown that the high concentration of humic acid enhances the stability of ZnO NPs via electrostatic and/or steric repulsion mechanism, consequently decreases their aggregation rate [19]. It can also alter NPs dissolution behavior through chelation and/or complexation [20]. However, the low concentration of a humic substance in water bodies may increase the agglomeration and sedimentation process $[16,21]$. While, low molecular weight NOM such as salicylic acid and citric acid, mostly found in lakes and rivers, may promote the dissolution of NPs and therefore elevate the toxicity of NPs in an aqueous environment $[19,22]$. Some researchers $[23,24]$ have reported the destabilizing effect of NOM on NPs in the presence of divalent cations under varying $\mathrm{pH}$ conditions, which may be ascribed to intra- and/or intermolecular bridging effect between the NOM and NPs, resulting aggregation of NPs. The aggregation and sedimentation behavior are integrated phenomenon based upon complicated interaction among various physicochemical properties of NPs and solution chemistry. Understanding the environmental fate and mobility of ZnO NPs is essential for properly assessing their toxicity and risk. However, studies reported in the literature are limited to "one-factor-at-a-time" experiments to determine the sedimentation behavior of ZnO NPs. The literature also seems insufficient to study the interactive behavior of factors affecting this phenomenon. Therefore, it is significant to comprehensively understand the role of environmental factors in aquatic environment influencing sedimentation behavior of $\mathrm{ZnO} N P s$ in heterogeneous matrices.

During last few decades, numerous statistical methods have been developed for analysis and optimization of experiment process parameters. Among them, the fractional factorial design based on Taguchi orthogonal array (OA) [25] utilizing the design of experiment approach (DOE), has been referred to $[26,27]$ as an efficient technique to study the effect of collective factors and their interaction. In this study, sedimentation behavior of $\mathrm{ZnO}$ NPs in various aqueous matrices was investigated using Taguchi standard $\mathrm{OA} \mathrm{L} \mathrm{L}_{27}\left(3^{13}\right)$ design matrix. The contribution and significance of individual and multiple environmental factors including, $\mathrm{pH}$, temperature, electrolyte and NOM types, 
their concentration, as well as interaction among several parameters, were systematically studied. Additionally, the applicability of this method was verified against sedimentation experiments in various environmental water samples. In this study, we estimated ZnO NPs sedimentation behavior through concentration measurement rather than particle size. This approach may be another way to assess sedimentation behavior of ZnO NPs in an aqueous environment.

\section{Materials and Methods}

\subsection{Chemicals and Materials}

The commercially available $\mathrm{ZnO}$ nanopowder (vendor reported particle size <50 nm), NOM including humic acid, salicylic acid and citric acid were purchased from Sigma-Aldrich (St. Louis, $\mathrm{MO}, \mathrm{USA})$, while potassium chloride $(\mathrm{KCl})$, sodium sulfate $\left(\mathrm{Na}_{2} \mathrm{SO}_{4}\right)$, magnesium chloride $\left(\mathrm{MgCl}_{2}\right)$, hydrochloric acid $(\mathrm{HCl})$ and sodium hydroxide $(\mathrm{NaOH})$ were obtained from the local suppliers. Nanopure water was used to prepare all stock solutions and synthetic environmental water. Prior to use, all glassware's were washed with $15 \% \mathrm{HNO}_{3}$ solution and then rinsed with deionized water.

\subsection{Preparation of Stock Solutions}

\subsubsection{Preparation of ZnO NPs Stock Solution}

The ZnO NPs stock solution was prepared by adding $100 \mathrm{mg}$ of $\mathrm{ZnO}$ nanopowder in $1 \mathrm{~L}$ of nanopure water. The suspension was subjected to probe-sonication using an ultrasonicator (ultrasonic cell crusher, Bio-safer 1200-90, Nanjing, China) in an ice-water bath to avoid uncontrolled heating at $25 \pm 1{ }^{\circ} \mathrm{C}$. Firstly, the effect of ultrasonic time periods (5-40 min) and power ranges (100-600 W) on the NPs distribution in suspension was investigated through turbidity measurement with (Hach Benchtop 2100N, Loveland, CO, USA) to obtain the optimum dispersion.

\subsubsection{Preparation of Inorganic Salt and NOM Solutions}

The stock solution of three common inorganic salts i.e., $\mathrm{KCl}, \mathrm{Na}_{2} \mathrm{SO}_{4}$ and $\mathrm{MgCl}_{2}$ with $1.0 \mathrm{M}$ IS were prepared and filtered through $0.45 \mu \mathrm{m}$ glass fiber filter. The stock solution of each NOM i.e., humic acid, salicylic acid and citric acid were prepared by adding $1000 \mathrm{mg}$ powder in $1 \mathrm{~L}$ nanopure water. The $\mathrm{pH}$ of the humic acid stock solution was adjusted to 10 using $0.1 \mathrm{M} \mathrm{NaOH}$ and stirred at $600 \mathrm{rpm}$ for $24 \mathrm{~h}$ to ensure complete dissolution. The detailed method can be referred elsewhere [28]. Prior to storage in dark at $4{ }^{\circ} \mathrm{C}$, all NOM stock solutions were filtered using $0.45 \mu \mathrm{m}$ glass fiber filter. The $\mathrm{pH}$ was adjusted to $7.0 \pm 0.1$ using $0.1 \mathrm{M} \mathrm{HCl}$.

\subsection{Characterization and Measurement}

The optical absorption measurement of ZnO NPs in ultraviolet-visible (UV-Vis) range was made in a spectrophotometer (Optizen, 2120 UV-Vis, Mecasys, Korea) at room temperature. The wavelength used in experiments ranged from $200-800 \mathrm{~nm}$, (see supplementary material). The $\mathrm{pH}$ and conductivity of water samples were analyzed using (HACH: HQ40d Portable pH, Conductivity, Oxidation-Reduction potential (ORP) and Ion-Selective Electrode (ISE) Multi-Parameter Meter) (Thermo Fisher Scientific, Waltham, MA, USA). The total organic carbon (TOC) content and inorganic elemental analysis were performed with TOC Analyzer (TOC-5000A, Shimadzu Corp, Kyoto, Japan) and Inductively Coupled Plasma Optical Emission Spectroscopy (ICP-OES: Model Varian, Agilent Technologies, Santa Clara, CA, USA) respectively. The zeta potential was measured with zeta potential analyzer (Zeta-sizer NanoZS, Malvern, Worcestershire, UK). The $\mathrm{N}_{2}$-Brunauer-Emmett-Teller (BET) surface area were also evaluated on the basis of nitrogen adsorption isotherms measured at $-196{ }^{\circ} \mathrm{C}$ using a gas adsorption apparatus (ASAP 2020, Micromeritics, Norcross, GA, USA). Furthermore, Fourier Transform Infrared Spectroscopy (FT/IR-4700, JASCO Analytical Instruments, Easton, PA, USA) in the 
range of 500-4000 $\mathrm{cm}^{-1}$ was conducted on pristine $\mathrm{ZnO}$ nanopowder and suspension for functional groups as well as bond analysis.

\subsection{Sedimentation Experimental Procedure}

The experiments were conducted in a standard sedimentation tube (height; $30 \mathrm{~cm}$, radius; $2 \mathrm{~cm}$ ) for $360 \mathrm{~min}(6 \mathrm{~h})$. The concentration of ZnO NPs in the tube was maintained at $100 \mathrm{mg} / \mathrm{L}$; inorganic salt and NOM solutions or environmental water samples were subsequently added. Then, the suspensions were immediately ultrasonicated to fully disperse the particle in the solution. The $\mathrm{pH}$ was adjusted to predetermined $\mathrm{pH}$ using the $0.1 \mathrm{M} \mathrm{HCl}$ or $0.1 \mathrm{M} \mathrm{NaOH}$. The sample of $1 \mathrm{~mL}$ was collected from each suspension at the $1 / 4$ height of the tube after $6 \mathrm{~h}$, then NPs concentration was monitored by measuring the absorbance of the taken sample. The ZnO NPs suspension has a white milky complex that can be detected through UV-Vis spectrophotometer (see Supplementary Material S1.2); our preliminary results show a good correlation of $\mathrm{ZnO}$ NPs concentration in the suspension with their absorbance (Figure S2B). Thus, it is possible to measure the residual concentration of NPs by measuring its absorbance using the equation below:

$$
C=0.0086 \times A-0.0116, R^{2}=0.9993
$$

where $C$ is the concentration of $\mathrm{ZnO} N P s(\mathrm{mg} / \mathrm{L}) ; A$ is the absorbance and $R$ is the correlation coefficient. Similarly, sedimentation efficiency (SE) of ZnO NPs in suspension was measured using:

$$
\alpha=\frac{C i-C t}{C i} \times 100
$$

where $\alpha$ is sedimentation efficiency; $C_{i}$ and $C_{t}$ are ZnO NPs initial and final concentration after the $6 \mathrm{~h}$ of sedimentation. Following this approach, three types of experiments were conducted with single factor i.e., $\mathrm{pH}$, electrolyte type and concentration, NOM type and concentration. The solution chemistry for each experiment are shown in Table 1.

Table 1. Experiment type and solution condition of single factor experiments.

\begin{tabular}{cc}
\hline Experiment Type & Solution Chemistry \\
\hline $\mathrm{A}(\mathrm{pH})$ & 3.0 to 12.0 \\
\hline & $\mathrm{KCl}(0.01$ to $100 \mathrm{mM})$ \\
$\mathrm{B}$ (Electrolyte type and concentration) & $\mathrm{Na}_{2} \mathrm{SO}_{4}(0.01$ to $100 \mathrm{mM})$ \\
& $\mathrm{MgCl}_{2}(0.01$ to $25 \mathrm{mM})$ \\
\hline & Humic acid $(0.5$ to $100 \mathrm{mg} / \mathrm{L})$ \\
$\mathrm{C}$ (NOM type and concentration) & Salicylic acid $(0.5$ to $100 \mathrm{mg} / \mathrm{L})$ \\
& Citric acid $(0.5$ to $100 \mathrm{mg} / \mathrm{L})$ \\
\hline
\end{tabular}

\subsubsection{Aggregation Kinetics}

The aggregation kinetics of ZnO NPs was determined according to the time-resolved optical absorbance measured at a wavelength of $370 \mathrm{~nm}$ with an interval of $6 \mathrm{~min}$ (Figure S1). All conditions for the aggregation measurements were the same unless otherwise stated and the samples were held in a quartz cuvette with the $1 \mathrm{~cm}$ light path. The relationship between settling rate of NPs and its aggregation kinetics in a fluid of known viscosity and density was developed with Stokes sedimentation theory [29]. This theory describes that the settling velocity of spherical particles is proportional to the square of the particle diameter and it sinks through a liquid column under the influence of gravity. The first-order kinetic equation as suggested in [21] given Equations (3) and (4) were obtained owing to the identical behavior of data presented in (Figure S3) with $\mathrm{R}^{2}=0.9909$.

$$
\mathrm{dC} / \mathrm{dt}=-\mathrm{kC}
$$




$$
\ln \mathrm{C}=\ln \mathrm{Co}-\mathrm{kt}
$$

where $t$ represents the time; $\mathrm{C}_{0}$ and $\mathrm{C}$ are $\mathrm{ZnO}$ NPs concentrations at zero and $\mathrm{t}$ timepoints, respectively, which are measured by the optical absorbance at 0 and $\mathrm{t}$ timepoints; and $\mathrm{k}$ is the sedimentation rate in $\left(\mathrm{h}^{-1}\right)$.

\subsubsection{Influence and Interaction of Multi-Environmental Factors}

The Taguchi OA design matrix has widely been used in engineering analysis, which is based on intraparametric interactions of different water chemistry parameters (see Supplementary Material S1.3). The temperature levels were set to simulate various environmental bodies conditions such as $(15,25$ and $35^{\circ} \mathrm{C}$ ), to indicate cold, temperate and tropical surface waters respectively. Six independent factors with three levels were selected in this study as mentioned in Table 2, (A) pH; (B) electrolyte concentration, (C) NOM concentration, (D) electrolyte type, (E) NOM type, and (F) temperature. Four relevant factors (two interactions for each $(\mathrm{A} \times \mathrm{B})$ and $(\mathrm{B} \times \mathrm{C})$ ) were considered, in addition, to calibrate the OA matrix three empty columns (shown as \#) were left. The OA $\mathrm{L}_{27}\left(3^{13}\right)$ matrix (standard three-level OA) was chosen to assign the factors and two variables interactions. The corresponding levels of interactions and empty columns were defined according to the altered matrix as shown in Table 3.

Table 2. Factors and levels for sedimentation experiment using Taguchi (OA).

\begin{tabular}{lcccccc}
\hline Factor & $\mathbf{p H}$ & $\begin{array}{c}\text { Electrolyte Conc; } \\
(\mathbf{m M})\end{array}$ & $\begin{array}{c}\text { NOM Conc: } \\
(\mathbf{m g} / \mathbf{L})\end{array}$ & $\begin{array}{c}\text { Electrolyte } \\
\text { Type }\end{array}$ & NOM Type & $\begin{array}{c}\text { Temperature } \\
\left({ }^{\circ} \mathbf{C}\right)\end{array}$ \\
\hline Level 1 & 7.0 & 25 & 5 & $\mathrm{KCl}$ & Humic acid & 15 \\
Level 2 & 8.0 & 50 & 10 & $\mathrm{Na}_{2} \mathrm{SO}_{4}$ & Salicylic acid & 25 \\
Level 3 & 9.5 & 100 & 25 & $\mathrm{MgCl}_{2}$ & Citric acid & 35 \\
\hline
\end{tabular}

\subsection{Preparation of Environmental Water Samples}

Six different environmental water samples were investigated in this study to understand the sedimentation and aggregation behavior of ZnO NPs. To simulate the water chemistry of natural seawater, underground water, freshwater and domestic wastewater, the samples were synthetically prepared in the lab. Two natural water samples including tap water from our laboratory at Sungkyunkwan University and industrial wastewater from metal processing industry located in Korea were collected. The detailed characteristic of samples and the method of preparation are provided in Supplementary Material S1.1 and Table S2 respectively.

\subsection{Data Analysis}

A univariate general linear model (GLM) with a Tukey's post hoc test was developed using Minitab 18.0 to estimate the significance and percentage contribution (\%) of factors as well as their interaction effect on the sedimentation behavior of $\mathrm{ZnO}$ NPs. Furthermore, normality and homogeneity of data were checked before conducting the analysis of variance (ANOVA). The definition and calculation of statistical terms have earlier been described in detail [27] and also shown in supplementary material. All data in the figures are presented in mean, standard deviation (SD) and each experiment was performed in triplicate. 
Table 3. Column assignment for the various factors and two interactions in the Taguchi $\mathrm{L}_{27}\left(3^{13}\right)$ orthogonal array (OA) and experimental SE values for ZnO NPs. (Elec; electrolyte, Conc; concentration, $\mathrm{L}_{1}, \mathrm{~L}_{2}, \mathrm{~L}_{3}$, are the average response at levels 1,2 and 3 respectively; $\mathrm{R}$ is the range, difference between the min and max average responses).

\begin{tabular}{|c|c|c|c|c|c|c|c|c|c|c|c|c|c|c|}
\hline \multirow[b]{2}{*}{ Trial No } & \multirow{2}{*}{$\frac{\mathrm{A}}{\mathrm{pH}}$} & \multicolumn{2}{|l|}{ B } & \multicolumn{4}{|c|}{$\mathrm{C}$} & & \multirow{2}{*}{$\begin{array}{c}\text { D } \\
\begin{array}{c}\text { Electrolyte } \\
\text { Type }\end{array}\end{array}$} & \multirow{2}{*}{$\frac{E}{\text { NOM Type }}$} & \multicolumn{3}{|c|}{$\mathbf{F}$} & \multirow[b]{2}{*}{$\mathrm{SE} \%$} \\
\hline & & $\begin{array}{l}\text { Elec. Conc; } \\
\text { (mM) }\end{array}$ & $(\mathrm{A} \times \mathrm{B})_{1}$ & $(\mathrm{~A} \times \mathrm{B})_{2}$ & $\begin{array}{l}\text { NOM Conc; } \\
\text { (mg/L) }\end{array}$ & $\#$ & $\#$ & $(B \times C)_{1}$ & & & $(\mathrm{~B} \times \mathrm{C})_{2}$ & $\begin{array}{c}\text { Temperature } \\
\left({ }^{\circ} \mathrm{C}\right)\end{array}$ & $\#$ & \\
\hline 1 & 7.0 & 25 & & & 10 & & & & $\mathrm{KCl}$ & Humic acid & & 15 & & 22.12 \\
\hline 2 & 7.0 & 25 & & & 25 & & & & $\mathrm{Na}_{2} \mathrm{SO}_{4}$ & Salicylic acid & & 25 & & 20.15 \\
\hline 3 & 7.0 & 25 & & & 50 & & & & $\mathrm{MgCl}_{2}$ & citric acid & & 35 & & 47.06 \\
\hline 4 & 7.0 & 50 & & & 10 & & & & $\mathrm{Na}_{2} \mathrm{SO}_{4}$ & Salicylic acid & & 35 & & 30.4 \\
\hline 5 & 7.0 & 50 & & & 25 & & & & $\mathrm{MgCl}_{2}$ & citric acid & & 15 & & 55.56 \\
\hline 6 & 7.0 & 50 & & & 50 & & & & $\mathrm{KCl}$ & Humic acid & & 25 & & 6.56 \\
\hline 7 & 7.0 & 100 & & & 10 & & & & $\mathrm{MgCl}_{2}$ & citric acid & & 25 & & 75.02 \\
\hline 8 & 7.0 & 100 & & & 25 & & & & $\mathrm{KCl}$ & Humic acid & & 35 & & 36.8 \\
\hline 9 & 7.0 & 100 & & & 50 & & & & $\mathrm{Na}_{2} \mathrm{SO}_{4}$ & Salicylic acid & & 15 & & 29.78 \\
\hline 10 & 8.0 & 25 & & & 10 & & & & $\mathrm{Na}_{2} \mathrm{SO}_{4}$ & citric acid & & 25 & & 28.94 \\
\hline 11 & 8.0 & 25 & & & 25 & & & & $\mathrm{MgCl}_{2}$ & Humic acid & & 35 & & 57.78 \\
\hline 12 & 8.0 & 25 & & & 50 & & & & $\mathrm{KCl}$ & Salicylic acid & & 15 & & 7.78 \\
\hline 13 & 8.0 & 50 & & & 10 & & & & $\mathrm{MgCl}_{2}$ & Humic acid & & 15 & & 65.56 \\
\hline 14 & 8.0 & 50 & & & 25 & & & & $\mathrm{KCl}$ & Salicylic acid & & 25 & & 26.67 \\
\hline 15 & 8.0 & 50 & & & 50 & & & & $\mathrm{Na}_{2} \mathrm{SO}_{4}$ & citric acid & & 35 & & 16.50 \\
\hline 16 & 8.0 & 100 & & & 10 & & & & $\mathrm{KCl}$ & Salicylic acid & & 35 & & 49.89 \\
\hline 17 & 8.0 & 100 & & & 25 & & & & $\mathrm{Na}_{2} \mathrm{SO}_{4}$ & citric acid & & 15 & & 41.40 \\
\hline 18 & 8.0 & 100 & & & 50 & & & & $\mathrm{MgCl}_{2}$ & Humic acid & & 25 & & 53.22 \\
\hline 19 & 9.5 & 25 & & & 10 & & & & $\mathrm{MgCl}_{2}$ & Salicylic acid & & 35 & & 47.41 \\
\hline 20 & 9.5 & 25 & & & 25 & & & & $\mathrm{KCl}$ & citric acid & & 15 & & 9.25 \\
\hline 21 & 9.5 & 25 & & & 50 & & & & $\mathrm{Na}_{2} \mathrm{SO}_{4}$ & Humic acid & & 25 & & 4.35 \\
\hline 22 & 9.5 & 50 & & & 10 & & & & $\mathrm{KCl}$ & citric acid & & 25 & & 39.12 \\
\hline 23 & 9.5 & 50 & & & 25 & & & & $\mathrm{Na}_{2} \mathrm{SO}_{4}$ & Humic acid & & 35 & & 28.6 \\
\hline 24 & 9.5 & 50 & & & 50 & & & & $\mathrm{MgCl}_{2}$ & Salicylic acid & & 15 & & 43.44 \\
\hline 25 & 9.5 & 100 & & & 10 & & & & $\mathrm{Na}_{2} \mathrm{SO}_{4}$ & Humic acid & & 15 & & 63.13 \\
\hline 26 & 9.5 & 100 & & & 25 & & & & $\mathrm{MgCl}_{2}$ & Salicylic acid & & 25 & & 78.0 \\
\hline 27 & 9.5 & 100 & & & 50 & & & & $\mathrm{KCl}$ & citric acid & & 35 & & 52.46 \\
\hline $\mathrm{L}_{1}$ & 35.90 & 27.21 & 43.49 & 38.28 & 46.70 & 35.69 & 39.30 & 35.64 & 27.90 & 37.58 & 38.26 & 36.60 & 39.20 & \\
\hline $\mathrm{L}_{2}$ & 38.59 & 34.63 & 33.12 & 42.30 & 39.31 & 39.50 & 37.65 & 39.72 & 29.28 & 37.05 & 38.05 & 38.01 & 36.27 & \\
\hline $\mathrm{L}_{3}$ & 40.61 & 53.30 & 38.60 & 34.60 & 29.05 & 39.85 & 38.20 & 38.25 & 58.10 & 40.60 & 38.90 & 40.80 & 37.69 & \\
\hline $\mathrm{R}$ & 4.71 & 26.09 & 10.37 & 7.7 & 17.65 & 4.16 & 1.65 & 4.08 & 30.20 & 3.55 & 0.85 & 4.20 & 2.93 & \\
\hline
\end{tabular}




\section{Results and Discussions}

\subsection{Characterization of ZnO NPs Solution}

Major physicochemical properties of $\mathrm{ZnO}$ nanoparticle are summarized in Table S1. The effect of ultrasonic time (5-40 $\mathrm{min})$ and power (100-600 W) on NPs particle distribution in solution was investigated. As shown in Figure S2A, the turbidity of ZnO NP suspension was jointly affected by both ultrasonic times as well as power. The optimum dispersion was obtained with 30-min sonication time and ultrasonic power of $400 \mathrm{~W}$. However, no significant difference in turbidity was observed after a further increase in ultrasonic time and power. While the Brunauer-Emmett-Teller (BET) specific surface area of the NPs was estimated to be $11.2 \mathrm{~m}^{2} / \mathrm{g}$. The zeta potential was measured at various $\mathrm{pH}$ values as shown in Figure S2B. The ZnO NPs of the stock suspension in nanopure water showed a positive charge with a zeta potential of $+19 \pm 1.5 \mathrm{mV}$. The zeta potential is positive between $\mathrm{pH} 5-9$ and approximately zero at $\mathrm{pH}$ 9.2, above which it becomes negative. These results are in good agreement with those reported in the literature [11,18,30].

According to the vendor, $6 \%$ of $\mathrm{Al}$ was used as a doping agent, therefore FT-IR was used to investigate the characterization of ZnO NPs (Figure S2C). In the FT-IR spectrums of ZnO NPs, the peak at approximately $685 \mathrm{~cm}^{-1}$ and $970 \mathrm{~cm}^{-1}$ corresponds to the stretching vibration of $\mathrm{Al}-\mathrm{C}$ bond and $\mathrm{Al}-\mathrm{O}$ stretching vibrations respectively [31,32]. The peak at $1375 \mathrm{~cm}^{-1}$ corresponds to the in-plane bending vibration or C-C stretching. The weak peaks at $2892-2972 \mathrm{~cm}^{-1}$ were due to symmetric and asymmetric stretching vibration of C-H bond respectively [33]. The absorption peak at approximately $3653 \mathrm{~cm}^{-1}$ represents the $\mathrm{O}-\mathrm{H}$ stretching vibration due to adsorbed water at the surface of the particle [34], while the peaks at $554 \mathrm{~cm}^{-1}$ correspond to the $\mathrm{Zn}-\mathrm{O}$ bond stretching [31]. These results indicate the presence of capping agent on the $\mathrm{ZnO}$ NPs. In addition, the presence of ZnO NP was evidence by UV-Vis spectra which showed a strong absorbance at a wavelength of $370 \mathrm{~nm}$ (Figure S2A,B).

\subsection{Single Factor Effect on Sedimentation}

\subsubsection{Effect of Solution $\mathrm{pH}$ on Sedimentation of $\mathrm{ZnO}$ NPs}

The sedimentation efficiency (SE) of $\mathrm{ZnO}$ NPs in solutions of various $\mathrm{pH}$ is presented in Figure $1 \mathrm{~A}$. The SE values at $\mathrm{pH} 9$ and 9.5 were about $80 \%$ and $85 \%$ respectively after $6 \mathrm{~h}$ of experiment, which was higher than any other $\mathrm{pH}$ value. These findings could be attributed to the closeness of $\mathrm{pH}$ of the suspension to point of zero charge $\left(\mathrm{pH}_{\mathrm{zpc}}\right)$ of $\mathrm{ZnO}$ NPs (Figure S2B). Previous studies also determined the $\mathrm{pH}_{\mathrm{zpc}}$ of $\mathrm{ZnO}$ NPs between 8.5 and 9.5 [6,13]. Therefore, particles have little or negligible charge at or near $\mathrm{pH}_{\mathrm{zpc}}$, leading to a substantial weakening in the repulsive forces among the NPs; thus, each collision between NPs and aggregates might cause particle adherence resulting in settling [30]. However, SE of ZnO NPs was also higher under acidic (3-6) and alkaline (10-12) conditions due to the dissolution and complexes region respectively [35]. The driving force under acidic conditions might be due to the presence of high concentration of protons, which can efficiently compress the EDL on the surface of NPs. The higher SE at alkaline conditions might be related to the formation of soluble hydroxide and hydroxy complexes [35,36], Therefore, to minimize this effect the remaining sedimentation experiments were conducted at circumneutral $\mathrm{pH}$. Moreover, the settling velocity and viscosity of $\mathrm{ZnO}$ NPs suspension at different temperatures were also evaluated as shown in Table S3. 

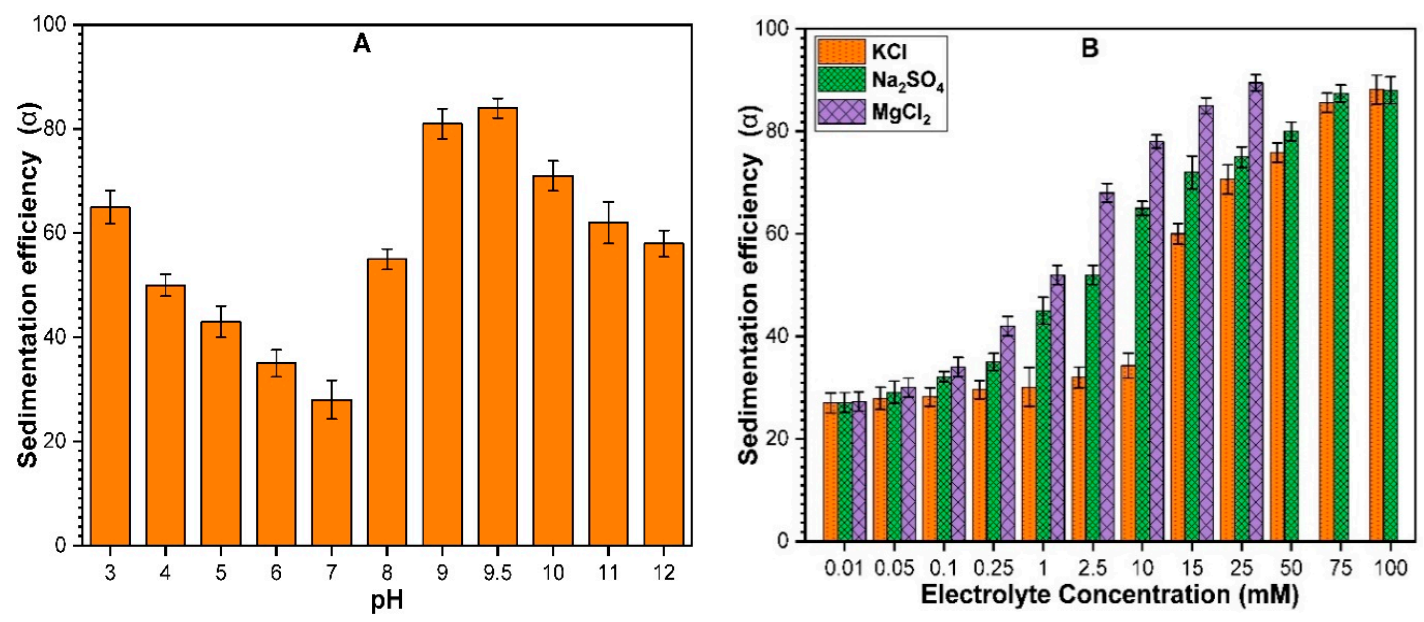

Figure 1. Sedimentation efficiency of ZnO NPs (100 mg/L), $\mathrm{pH} 7$ and temperature $25 \pm 1{ }^{\circ} \mathrm{C}$ after $6 \mathrm{~h}$ showing; (A) various $\mathrm{pH}$ ranges; (B) electrolyte concentration of $\mathrm{KCl}, \mathrm{Na}_{2} \mathrm{SO}_{4}$ and $\mathrm{MgCl}_{2}$.

\subsubsection{Effect of Monovalent and Divalent Cations on Sedimentation of ZnO NPs}

The stability and aggregation of metallic NPs in aqueous solution depend to a large extent on the ionic strength and salt type. The effect of monovalent and divalent ions on the ZnO NPs stability were studied with $0.01-100 \mathrm{mM} \mathrm{KCl}, \mathrm{Na}_{2} \mathrm{SO}_{4}$ and $0.01-25 \mathrm{mM} \mathrm{MgCl}_{2}$ at $\mathrm{pH}$ 7. As shown in Figure 1B, the SE of ZnO NPs suspensions showed a significant increase at higher concentration of each electrolyte. For instance, at low concentration i.e., $0.01 \mathrm{mM}$ showed SE of about $28-30 \%$ irrespective of electrolyte type. However, SE becomes $90-92 \%$ at $100 \mathrm{mM}$ concentration of monovalent ions and $25 \mathrm{mM}$ concentration of divalent ions (Figure 1B). This behavior of ZnO NPs coincides with previously reported results $[30,37]$. This may be attributed to the fact that with increasing the ionic strength of monovalent, the electrostatic repulsion is screened and the energy barrier shrinks [38].

However, in case of divalent cations, simultaneous effect of EDL compression and neutralization of surface charge of NPs induced by counter ions resulted in destabilization and subsequent aggregation $[15,21]$. Our results were consistent with previous studies that the neutralization effect from counter ions played a significant role than the compressive effect from co-ions $[36,39]$.

\subsubsection{Impact of NOM on the Sedimentation of ZnO NPs}

The NOM, such as humic acid, salicylic acid and citric acid, may adsorb onto the surface of ENPs that may increase the stability of NPs. The effect of NOM on sedimentation and stability of $\mathrm{ZnO}$ NPs were investigated with NOM type and concentration. The SE plots and zeta potential are shown (Figure 2A,B). The SE of ZnO NPs was enhanced, i.e., 39-48\%, in the presence of low concentration of $1 \mathrm{mg} / \mathrm{L}$ humic acid and $2.5 \mathrm{mg} / \mathrm{L}$ salicylic acid respectively, as compared in the absence of both NOM (Figures $1 \mathrm{~A}$ and 2A). The ZnO NPs surface potential was positively charged at circumneutral $\mathrm{pH}$ (Figure S2B), while the surface potential decreased with the increase of both NOM concentrations (Figure 2B), and it closed to IEP at low concentrations. This phenomenon might be attributed to the charge neutralization, which occurs when the existing surface charge of NPs are departed by the charge of the adsorbed NOM molecules at appropriate concentration [30]. Additionally, when there is little to no charge on the surface of NPs, the minimum adsorption of NOM occurs, thus particle sedimentation rises at low concentration [40]. However, low concentration of citric acid, i.e., $1 \mathrm{mg} / \mathrm{L}$ in suspension, reduces the SE to 22\% (Figure 2A) which can be attributed to the presence of three carboxylic groups in citric acid that might impart more negative charges on the NPs surface (Figure 2B), as compared to humic acid and salicylic acid [21,30].

On the contrary, the SE was significantly suppressed upon an increase in the concentrations of humic acid and salicylic acid i.e., 2.5-10 mg/L (Figure 2A). However, the SE of $\mathrm{ZnO}$ suspension 
becomes stable with further increase in the concentration of both NOM to $100 \mathrm{mg} / \mathrm{L}$, thus showing the negligible effect on settling (Figure 2A). Such phenomena might result from the effect of steric hindrance imposed by the adsorbed NOM on the ZnO NPs [36,40]. Furthermore, the presence of higher concentration of NOM reversed the surface potential of $\mathrm{ZnO}$ NPs from positive to negative (Figure 2B). This indicates that negatively charged multiple functional carboxylates as well as phenolate groups attach to the surface of $\mathrm{ZnO}$ NPs [41]. Another possible reason for this phenomenon may be ascribed to the electro steric repulsion between the NOM-coated NPs that may become more important at higher NOM concentrations $[16,18]$. However, the presence of $(2.5-25 \mathrm{mg} / \mathrm{L})$ citric acid induced a dose-dependent decline in SE of NPs, while SE remarkably increased at $100 \mathrm{mg} / \mathrm{L}$ concentration (Figure 2A). This suggests the existence of three carboxylic groups in citric acid which are mostly deprotonated and might contribute more negative charges on the particle surface after ionization at neutral $\mathrm{pH}\left(\mathrm{pKa}_{1}=3.13, \mathrm{pKa}_{2}=4.76\right.$ and $\left.\mathrm{pKa}_{3}=6.40\right)[16,30,42]$. This causes a significant decrease in NPs Van der Waals (vdW) forces, but an increase in repulsive electrostatic forces between ZnO NPs. In addition, a part of that carboxylic groups in the citric acid may replace the abundant hydroxyl on the metal oxide surface and combine with metal cations forming a single molecular adsorbed layer [43]. This also specifies the role of electrostatic interactions in the presence of NOM, thereby stabilizing NPs suspension. These results strongly indicate that at high NOM concentrations, a different mechanism may be involved, which affects the surface potential and enhances the stability of NPs.
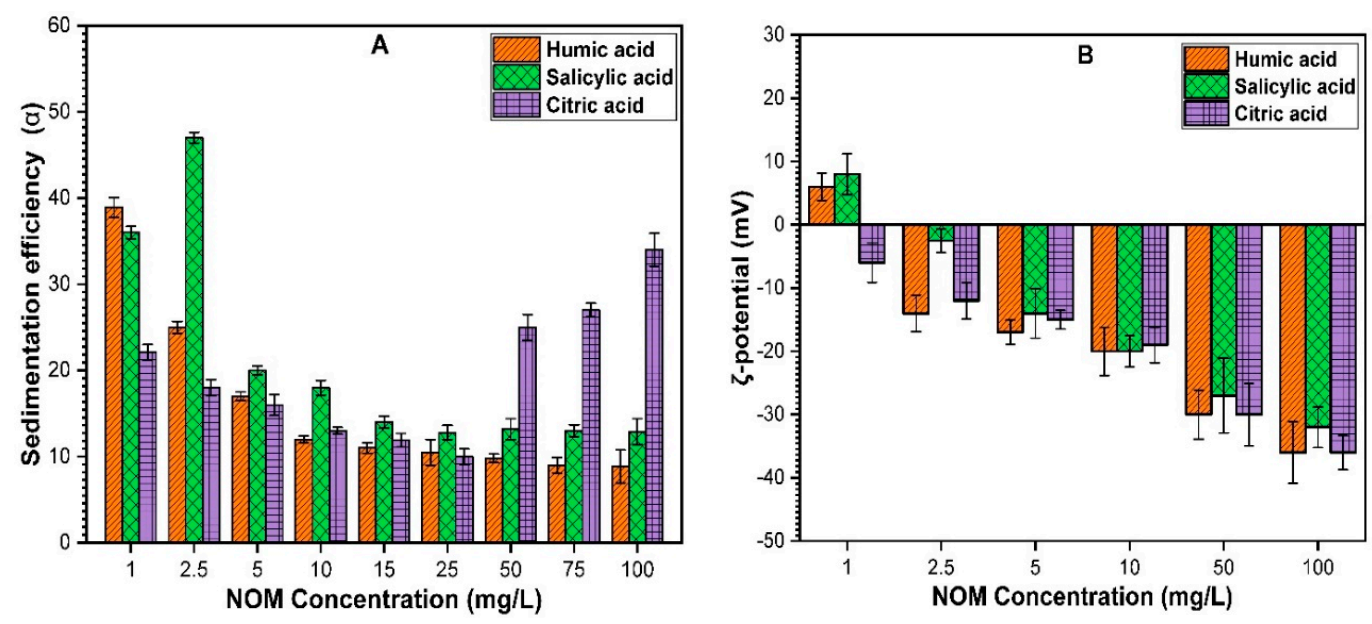

Figure 2. At $\mathrm{pH} 7$ and concentration range (1-100 $\mathrm{mg} / \mathrm{L}$ ) of each NOM showing (A) sedimentation efficiency; (B) zeta potential of ZnO NPs in the aqueous solution.

\subsubsection{FT-IR Analysis Pristine NOM and ZnO-NOM Complexes}

The adsorption of NOM on mineral hydroxide plays a vital role in the evaluation of the speciation of toxic metal ions released in the environment because both have variable surface charges that may alter adsorption. The FT-IR spectra of ZnO NP before and after interaction with NOM molecules in solution was studied for possible bonding of functional groups on the NPs surface. The peaks at 2974-2980 $\mathrm{cm}^{-1}$ were assigned to symmetric and asymmetric stretching in $\mathrm{C}-\mathrm{H}$ bond, respectively $[33,44]$. The peak that appeared at approximately $\sim 2353 \mathrm{~cm}^{-1}$ is attributed to the $\mathrm{CO}_{2}$ molecule present in the citrate and air [32]. The peaks in low-frequency range $1500-1750 \mathrm{~cm}^{-1}$ including $1722 \mathrm{~cm}^{-1}$ are assigned to $\mathrm{C}=\mathrm{O}$ stretching of the carbonyl and carboxylic acids [44]. The peaks around 1565 and $1656 \mathrm{~cm}^{-1}$ are assigned to $\mathrm{C}=\mathrm{O}$ stretching vibration of double bonds in ketones and phenols [45]. The peaks in the range $\sim 1400-950 \mathrm{~cm}^{-1}$ are ascribed to the enrichment of aliphaticor carbohydrate-OH functional groups [35]. In comparison with the pristine $\mathrm{ZnO}$ (Figure S2C), ZnO-NOM complexes (Figure $3 \mathrm{~A}-\mathrm{C}$ ) show a new peak with little shift in the carboxylate (-COO-) asymmetric and symmetric stretch at $\sim 1646,1633$ and $1639 \mathrm{~cm}^{-1}$ respectively, thus confirming the presence of oxygen-containing functional groups on the surface of $\mathrm{ZnO}$ NPs [46,47]. Among various 
functional groups of humic acid and salicylic acid, carboxylic (-COO-) and phenolic (-ArO-), amine groups have strong potential for chelation with metal ions $[39,46]$. The metal complexion may further facilitate more crystal planes and surface defects to the humic acid and promote dissolution of $\mathrm{ZnO}$ NPs. Interestingly, the citric acid sample shows a significant shift of $83 \mathrm{~cm}^{-1}$ i.e., 1722 to $1639 \mathrm{~cm}^{-1}$ in carboxylate (-COO-) group (Figure $3 \mathrm{C}$ ), indicating strong inner sphere complexation with the $\mathrm{ZnO}$ surface $[38,42]$. In addition, the strong adsorption may be either via polynuclear-polydentate linkage or mononuclear-polydentate linkage between citrate and $\mathrm{ZnO}$, thus resulting in weakened bonds in the metal-oxygen surface due to polarization [48,49]. Similar observations were reported in earlier studies [35,36], that enhanced release of $\mathrm{Zn}^{+2}$ may be expected due to ligand-promoted dissolution. As such, it is thought that NOM-coated ZnO NPs might be formed via bridging and coating of functional groups on the NPs surface due to their dynamic adsorption potential $[45,48]$.
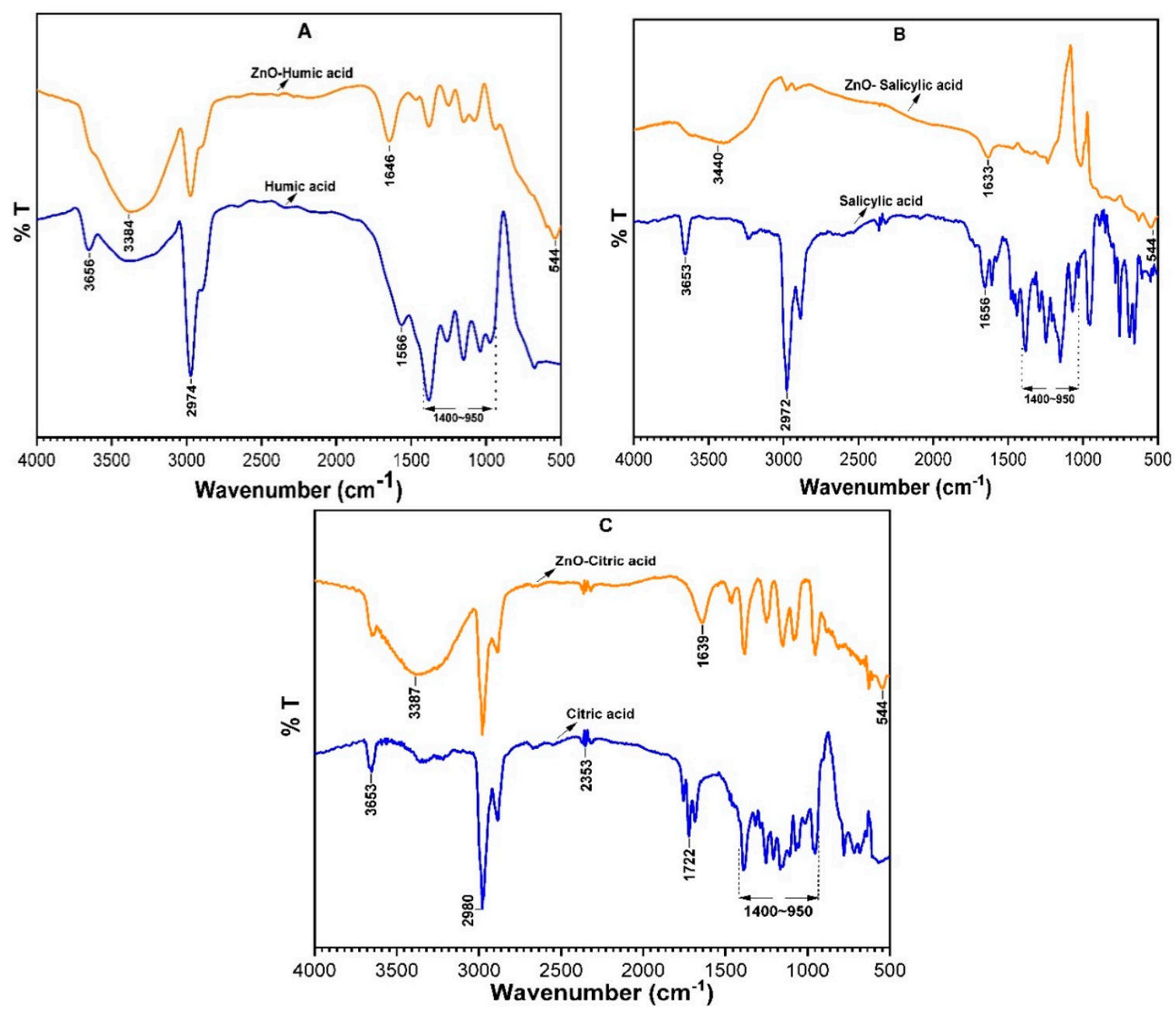

Figure 3. The Fourier transform infrared (FT-IR) spectra of ZnO NPs after interaction with (100 mg/L) concentrations: (A) Humic acid; (B) Salicylic acid; (C) Citric acid solution at $\mathrm{pH} 7$.

\subsubsection{ZnO NPs Aggregation Kinetics Exposed to Various Environmental Factors}

The NPs can aggregate and settle out of the water column at varying rates, depending on their surface properties and properties of the solution in which they are dispersed. The effect of various environmental factors on aggregation kinetics of ZnO NPs is shown in (Figure 4A-E). The steepest aggregation curve (Figure 4A) and maximum sedimentation rate of $\mathrm{ZnO}$ NPs were observed at $\mathrm{pH} 9$, near to $\mathrm{pH}_{\mathrm{zpc}}$ (Table 4), while a gentle curve and a significant decrease in settling rate could be found at $\mathrm{pH} 3$ and 12, far from $\mathrm{pH}_{\mathrm{zpc}}$ (Figure $4 \mathrm{~A}$ ). Many studies have reported that at or near $\mathrm{pH}_{\mathrm{zpc}}$, the 
electrostatic repellency between particles become negligible [18]. Moreover, the enhancement in the settling rate of NPs was observed at higher electrolyte concentration of monovalent cations i.e., $\mathrm{K}^{+}$, $\mathrm{Na}^{+}$, and low concentration of divalent cations i.e., $\mathrm{Mg}^{2+}$ further accelerated the sedimentation rate (Figure 4B). It is likely that the higher charges of cations effectively weaken the inter-particle repulsions, thus decreasing the stability of ZnO NPs [38]. In addition, rate value (k) also increased sharply, indicating that a minimum salt concentration required for rapid agglomeration should be reached, which is known as the Critical Coagulation Concentration (CCC), thus leading to high aggregation rate (Table 4). This has practical implications in the areas where water of varying salinity mixes, such as in estuarine environments. As illustrated, ZnO NP and other ENPs may settle down quickly in the water column while moving from areas of low to high salt concentrations. A similar phenomenon was reported in cases of $\mathrm{MnO}_{2}$ and Ag NPs [5,50].
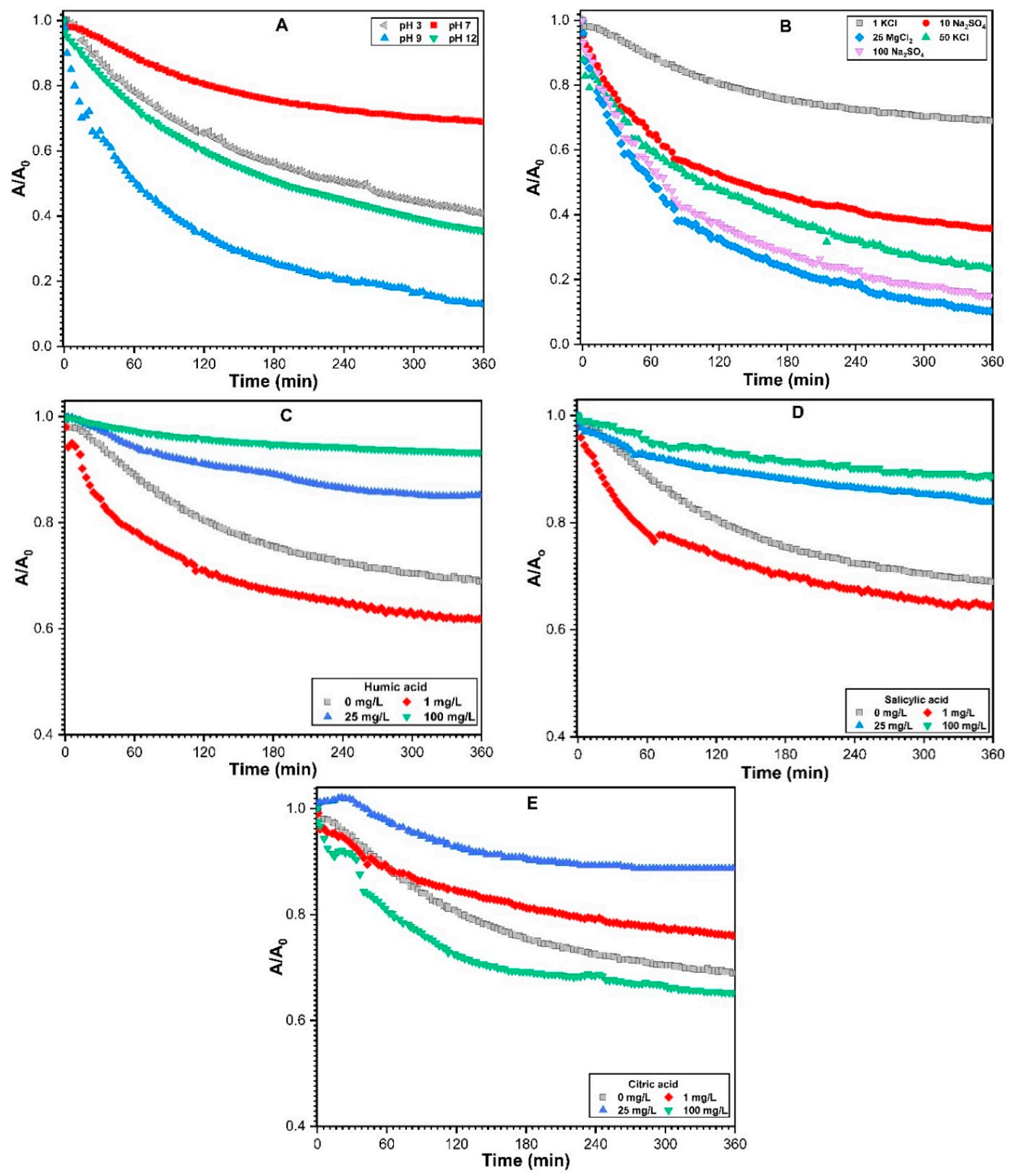

Figure 4. Representative aggregation profiles of $\mathrm{ZnO}$ NPs $(100 \mathrm{mg} / \mathrm{L})$ at $\mathrm{pH} 7$ with varying (A) $\mathrm{pH}$; (B) electrolyte concentration and type; (C) humic acid; (D) salicylic acid; (E) citric acid (please not the change of scale in graph (C-E)). 
Furthermore, the sedimentation curve became mildly steeper in the presence of lower concentration ( $1 \mathrm{mg} / \mathrm{L}$ ) of humic acid and salicylic acid, indicating low concentration of both NOM unstable the NPs, while the higher concentration i.e., (25-100 mg/L) impedes the aggregation process (Figure 4C,D). This suppression happened due to increased adsorption of organic acid on the NPs surface, Thus, the stability of suspension was enhanced markedly [40,42], whereas the first-order kinetics model did not fit well with the aggregation curve (Table 4). The presence of a lower concentration of citric acid (1-10 mg/L) lowers the settling rate than those in the absence of NOM (Figure 4E). There was, however, very little variation in settling performance of $\mathrm{ZnO}$ NPs at higher concentration i.e., $100 \mathrm{mg} / \mathrm{L}$ of citric acid (Table 4).

Table 4. Sedimentation rate at various $\mathrm{pH}$, electrolyte, NOM type and their concentrations.

\begin{tabular}{cccccccc}
\hline Environmental Parameters & $\mathbf{k}\left(\mathbf{h}^{-\mathbf{1}}\right)$ & $\mathbf{R}^{\mathbf{2}}$ & \multicolumn{2}{c}{ Environmental Parameters } & $\left.\mathbf{k} \mathbf{( h}^{\mathbf{- 1}}\right)$ & $\mathbf{R}^{\mathbf{2}}$ \\
\hline & 3 & 0.1507 & 0.9975 & NOM type & Conc. (mg/L) & & \\
$\mathrm{pH}$ & 7 & 0.0620 & 0.9986 & Humic Acid & 1 & 0.0808 & 0.9865 \\
& 9 & 0.3473 & 0.9876 & & 25 & 0.0267 & 0.9275 \\
& 12 & 0.1738 & 0.9981 & & 100 & 0.0118 & 0.8509 \\
\hline & \multicolumn{2}{c}{ Electrolyte Conc. $(\mathrm{mM})$} & & Salicylic Acid & 1 & 0.0722 & 0.9781 \\
\hline \multirow{2}{*}{$\mathrm{KCl}$} & 1 & 0.0620 & 0.9987 & & 25 & 0.0295 & 0.9322 \\
& 50 & 0.2431 & 0.9879 & & 100 & 0.0202 & 0.7876 \\
\hline \multirow{2}{*}{$\mathrm{Na}_{2} \mathrm{SO}_{4}$} & 10 & 0.1714 & 0.9932 & Citric Acid & 1 & 0.0457 & 0.9237 \\
& 100 & 0.3172 & 0.9943 & & 25 & 0.0199 & 0.8401 \\
\hline $\mathrm{MgCl}_{2}$ & 25 & 0.3786 & 0.9914 & & 100 & 0.0713 & 0.8048 \\
\hline
\end{tabular}

\subsubsection{Influence of Multi-Environmental Parameters on ZnO NPs Sedimentation}

The NPs sedimentation process may limit the release of metal ions to a considerable extent, which contributes towards bioavailability and toxicity to aquatic species. The average $\mathrm{SE}$ response $\left(\mathrm{L}_{1}, \mathrm{~L}_{2}, \mathrm{~L}_{3}\right)$ range analysis $(\mathrm{R})$ corresponding to each level and variables are shown in Table 3. The experiments were conducted in triplicate and the average responses with the relative standard deviation (RSD) were reported. The average values for individual factors allow comparison between the levels and prediction in the range analysis. The results of range analysis indicated that the electrolyte type and concentration were the most dominant factor followed by NOM concentration, $\mathrm{pH}$, temperature and NOM type respectively (Table 3 ). The ANOVA results revealed that the factors including $\mathrm{pH}, \mathrm{NOM}$ type, temperature and both interaction between $(\mathrm{A} \times \mathrm{B})$ and $(\mathrm{A} \times \mathrm{C})$ showed insignificant impact on $\mathrm{SE}$, while the remaining factors were found statistically significant at $(p<0.001,0.05)$ (Table 5). The percentage contribution due to errors, estimated from empty columns, was around $1.12 \%$, which can be explained by the result from some overlooked potential interactions among $(\mathrm{A} \times \mathrm{E})$ and $(\mathrm{E} \times \mathrm{F})$ due to protonation/deprotonation effect caused by $\mathrm{pH}$, potential charge reversal capacity and/or complexation of cations (i.e., $\mathrm{Mg}^{2+}, \mathrm{K}^{+}, \mathrm{Na}^{+}$) with organic compounds $[38,46]$.

Moreover, Figure 5 shows that electrolyte type and concentration were found to be the most significant factors. Among other factors, divalent cations were also a dominant factor in enhancing the sedimentation of ZnO NPs. The ANOVA estimates were around 47.03 and $29.08 \%$ contribution of electrolyte type and concentration respectively (Table 5). This might be attributed to the rapid adsorption of divalent cations on the surface of NOM and NPs, as a consequence of the binding of $\mathrm{Mg}^{2+}$ to carboxylate functional groups of the NOM ( $\mathrm{Mg}^{2+}-\mathrm{NOM}$ complexes), hence neutralizing the negative charges and reducing the absolute zeta potential of the solution [37]. The Theory of Derja-Guin-Landau-Verwey-Overbeek (DLVO) further explains that the stability of colloidal particle in the aqueous environment is determined by the sum of vdW forces and EDL repulsions [50]. In addition, $\mathrm{MgCl}_{2}$ salts are effective with unstable the $\mathrm{ZnO}$ as well as compressing the EDL on the surface of the NPs. As a result, particle agglomeration/sedimentation occurs with increasing surface area of NPs [28]. The NOM concentration was another key factor, which contributes about $13 \%$ of the variation 
in the matrix experiment (Table 5). The amount of organic matter adsorbed on the metal surface may vary among types, concentration and their adsorption capacities on NP [40,43]. Different functional groups of organic matter have a tendency to attach on ZnO NPs surface and undergo ligand exchange through weakening Zinc-Oxygen bond [49,50]. Hence the affinity of organic matter towards the metal surface and amount adsorbed may directly or indirectly relate to NPs aggregation, which may affect the overall sedimentation behavior of ZnO NPs in the system [30].

Table 5. Result of ANOVA for ZnO NPs sedimentation in the Taguchi $\mathrm{L}_{27}\left(3^{13}\right)$ OA design matrix.

\begin{tabular}{cccccc}
\hline Variance Parameters & $\begin{array}{c}\text { Degree of } \\
\text { Freedom }\end{array}$ & $\begin{array}{c}\text { Sum of } \\
\text { Squares (SS) }\end{array}$ & $\begin{array}{c}\text { Mean } \\
\text { Squared (MS) }\end{array}$ & F Ratio & \% Contribution \\
\hline pH (A) & 2 & 100.18 & 50.09 & $0.80^{\mathrm{a}}$ & $0.90 \%$ \\
Electrolyte conc. (B) & 2 & 3248.55 & 1624.28 & $25.95^{\mathrm{b}}$ & $29.08 \%$ \\
NOM conc. (C) & 2 & 1442.27 & 721.13 & $11.52^{\mathrm{b}}$ & $12.91 \%$ \\
Electrolyte Type (D) & 2 & 5253.95 & 2626.97 & $41.98^{\mathrm{c}}$ & $47.03 \%$ \\
NOM Type (E) & 2 & 65.59 & 32.80 & $0.52^{\mathrm{a}}$ & $0.59 \%$ \\
Temperature (F) & 2 & 77.25 & 38.63 & $1.85^{\mathrm{a}}$ & $0.69 \%$ \\
(A $\times$ B) & 4 & 753.9 & 188.47 & $3.01^{*}$ & $6.75 \%$ \\
(B $\times$ C) & 4 & 104.27 & 26.06 & $0.41^{*}$ & $0.93 \%$ \\
Error & 6 & 125.14 & 62.57 & & $1.12 \%$ \\
Total & 26 & 11171.1 & 5329.285 & & $100.00 \%$ \\
\hline
\end{tabular}

${ }^{a}$ Critical value is $5.14(p<0.05),{ }^{\mathrm{b}} 10.92(p<0.01) .{ }^{\mathrm{c}}$ Critical value is $27.00(p<0.001)$. while ${ }^{*}$ shows not significant. $X$ represents the interaction between two factors.

Figure 5 shows that in the presence of divalent cations, NOM might increase the NPs aggregation at low mass concentrations (e.g., $10 \mathrm{mg} / \mathrm{L}$ ), due to neutralization of NPs surface, which is attributed to the formation of a bridge among cations and NOM [20,21]. The previous studies support our findings [24], that both $\mathrm{Ca}^{2+}$ and $\mathrm{Mg}^{2+}$ could bridge with the NOM molecules, resulting in enhanced aggregation of gold nanoparticles (Au NPs). These results indicate hetero-aggregation of NOM molecules and ZnO NPs in presence of a high concentration of divalent cations. However, it is difficult to separate between divalent cation-induced aggregation of NOM molecule and direct aggregation of $\mathrm{ZnO}-\mathrm{NOM}$ complex. Hence, further investigation on the NOM surface adsorption and cation induced aggregation on ZnO NPs is needed. In contrast, high NOM mass content (i.e., $50 \mathrm{mg} / \mathrm{L}$ ) could still stabilize the NPs in the presence of high valent ions (Figure 5). This indicates that steric hindrance due to adsorption NOM on NPs surface combined with electrostatic effect was the predominant mechanism behind the stabilization of ZnO NPs. Similar results were reported in the previous studies [23], where silver nanoparticle (Ag NPs) suspension containing NOM and $\mathrm{Ca}^{2+}$, stabilized the particle by imparting the steric repulsion hence overcoming the electrostatic destabilization effect of the divalent ion. Thus, increased stability NPs in the presence of NOM may result in additional toxicity to sensitive species in combined toxicity from ions.

$\mathrm{pH}$ and temperature are often considered an influential factor on NP sedimentation [19,20]; they only contributed around $1 \%$ in the matrix experiment (Table 5). For instance, little increase in SE was observed at $\mathrm{pH} 9.5$ (Figure 5), due to nearness to $\mathrm{pH}_{\mathrm{zpc}}$, whereas at $\mathrm{pH} 7.8$ less settling might be due to modulating the protonation/deprotonation equilibrium and electrostatic repulsion [6]. In addition, an increase of adsorption of NOM on the NP surface may lead to disaggregation [50]. The slight increase in the SE was observed with increase in temperature (Figure 5). However, this difference was insignificant at 95\% confidence level (Table 5). The collision frequency and Brownian motion among NPs may increase at high temperature, which increases vdW attractive forces and reduces EDL repulsive forces thus bind NPs to form agglomerates [30,50]. The variation in temperature may also alter some solution properties such as viscosity, density, activity and ion mobility [18]. In addition, the ANOVA result of interaction between (ISxpH) and (ISxNOM) was found to be insignificant $(p<0.05)$. The results clearly show that the effect of an individual factor on sedimentation behavior of $\mathrm{ZnO}$ was predominant when compared with their interactions. This suggests that interaction between two factors in the system may counterbalance individual effects and present a combined weaker effect. 
Therefore, based on the above results and discussion it is inferred that in the integrated environmental system, the presence of other factors may affect the sedimentation behavior of $\mathrm{ZnO}$ NPs.

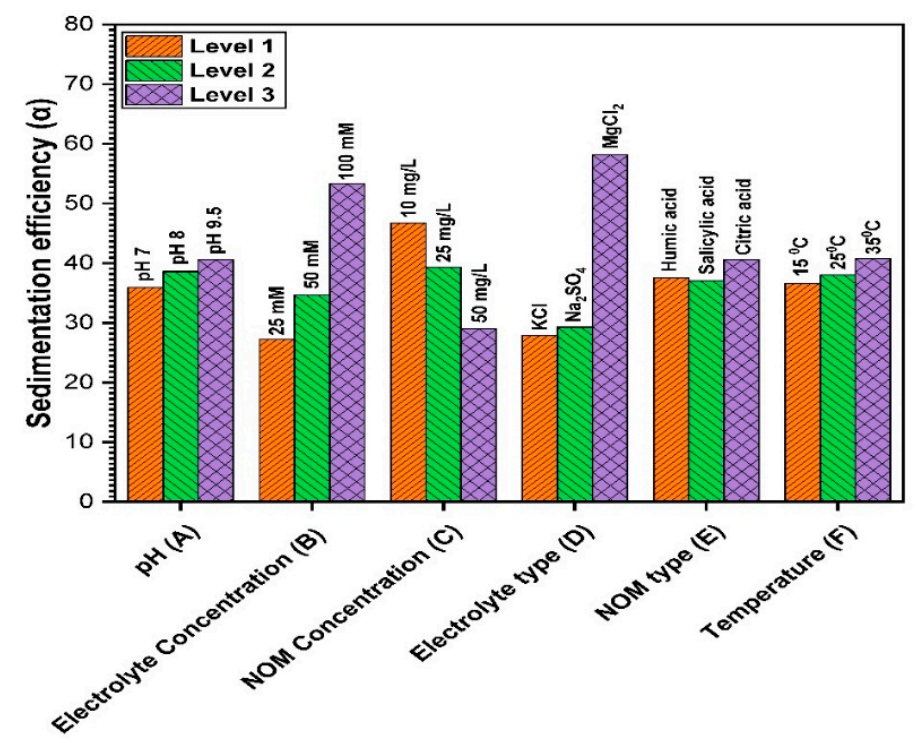

Figure 5. Effect of each level, $\mathrm{pH}$, IS and NOM concentration, NOM and electrolyte type, and temperature significant factors on average SE.

\subsubsection{Sedimentation Behavior of ZnO NPs in Aquatic Environments}

The NPs are currently not regarded as contaminants but their stability in water is essential in assessing their potential risk upon release/spill events. The sedimentation and aggregation behavior of $\mathrm{ZnO}$ NPs in various synthetic and natural waters were investigated (Figure 6A,B). The aggregation of seawater (SW), domestic wastewater (DWW) and groundwater (GW) increase rapidly with time. In contrast, NPs were quite stable in remaining tested waters and slowly aggregates (Figure 6B). The $\mathrm{pH}$ values of industrial wastewater (IWW), tap water (TW) and freshwater (FW) were 7.56, 7.02 and 6.90 respectively, which were far away from the $\mathrm{pHzpc}$ of $\mathrm{ZnO}$ NPs. The concentration of common ions and other elements in the IWW, DWW and SW was higher than other tested waters, resulting in high IS and conductivity (Table S2). This phenomenon is consistent with our results and previous studies, which report that NPs are unstable in high IS suspension [38]. Moreover, the SE of ZnO NPs decreases significantly, following the order of environmental water samples as (SW $>$ DWW > GW $>$ FW $>$ TW $>$ IWW) (Figure 6A). However, the dissimilar behavior of IWW indicates some other phenomena beyond the NPs stabilization.
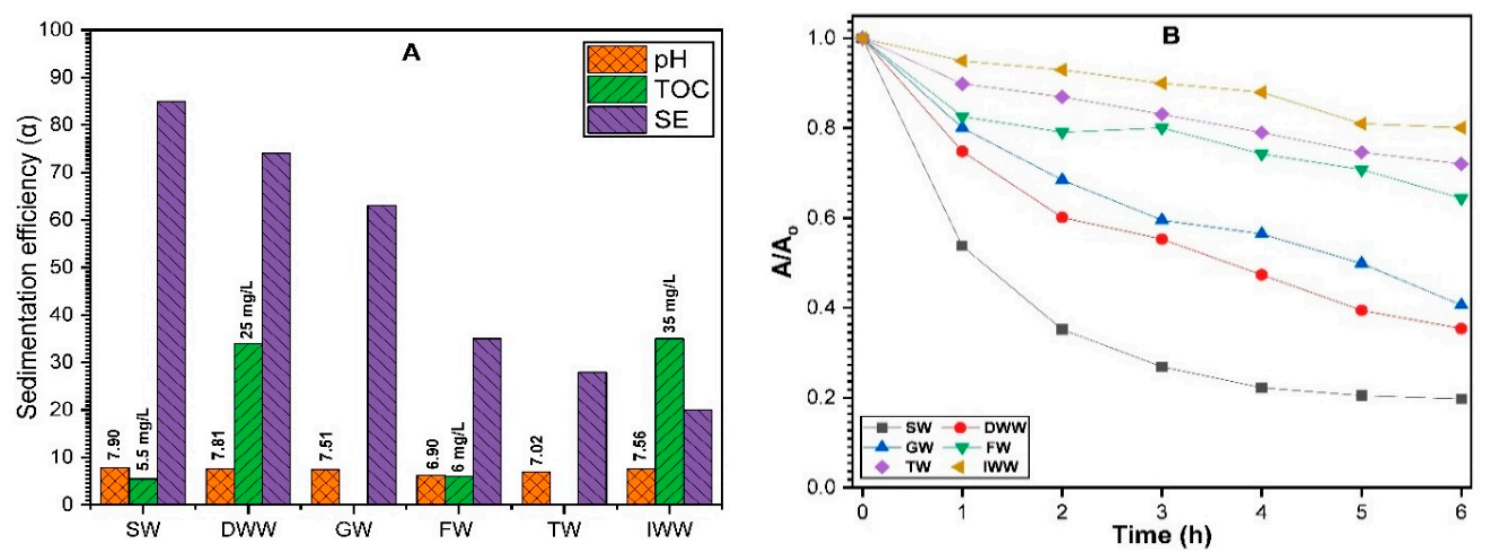

Figure 6. Across various tested waters showing; (A) sedimentation efficiency; (B) aggregation rate. 
Meanwhile the enhanced aggregation of ZnO NPs in synthetic seawater was due to the formation of hydrozincite [39]. Furthermore, the concentration of the counter-ions exceeds the CCC value for inverting the surface potential, and the dosage effect of the electrolyte would be mitigated. Consequently, the concentration of the $\mathrm{Cl}^{-}$and $\mathrm{SO}_{4}{ }^{-2}$ ions in the DWW was much higher than other waters, which might have neutralized or reversed the surface potential of NPs and therefore slow down the aggregation rate [49]. In the case of IWW, high TOC content and possible interference of metal ions such as arsenic ( $\mathrm{As}$ ) and antimony ( $\mathrm{Sb}$ ) may have contributed to the stability of NPs. According to literature NOM such as polyethene glycol, amino acid, humic acid, fulvic acid, and alginate $[16,24,40]$ has the ability to stabilize NPs, even antagonize the aggregation promoting effect from the electrolytes [40]. In addition, metal ions (present in polluted water sample) may induce the cross-linking of ZnO NPs by the target metal ion by coordinating bonding, leading to stabilization of NPs $[46,47]$. Thus, further studies should be conducted to investigate different metal ions effect on the NPs aggregation and complexation mechanism in real waters and environmentally relevant conditions.

\subsection{Environmental Implications}

This study provides some insights into the stability of ZnO NPs in the aquatic environment in terms of sedimentation and aggregation, which are a key process in determining the fate, mobility and bioavailability of NPs in the system. The present study was conducted at high ZnO NPs concentration, that may be expected in a spill event and/or is appropriate for laboratory conditions in ecotoxicological research. The dissolution of $\mathrm{ZnO}$ NPs results in the release of $\mathrm{Zn}^{+2}$ ions that are known to be toxic to most aquatic species; a process such as sedimentation that limits the release of these ions may reduce the potential risk. Our results highlight that ZnO NPs were generally unstable in suspension with the low NOM, high electrolyte concentration and temperature, while a high concentration of NOM sterically stabilized and/or chelate the NPs resulting in less NPs aggregation. Furthermore, it appears that in the aquatic environment, the transformation of the ZnO NPs may occur in the presence of other interfering metal ions. Factors such as the type of NOM, ratio between NP and NOM, cations, size of primary particle and temperature of receiving water bodies may be likely to play a critical role in the aggregation of the NPs. Therefore, these results underscore the challenge of predicting environmental risks posed by ENPs, which requires careful integration of complex physicochemical interactions between ENPs and various parameters.

\section{Conclusions}

In this study, we systematically investigate the influence of single and multi-environmental factors on the sedimentation and aggregation behavior of $\mathrm{ZnO}$ NPs at environmentally relevant conditions. The Taguchi OA $\mathrm{L}_{27}\left(3^{13}\right)$ design matrix combine with ANOVA was used to evaluate the main and interactive effect of multi-factors i.e., $\mathrm{pH}$, temperature, electrolyte type and concentration, NOM type and concentration. The results of single factor indicated that sedimentation of $\mathrm{ZnO}$ NPs was enhanced at or near $\mathrm{pH}_{\mathrm{zpc}}$, high electrolyte concentration and specifically divalent cations. However, the stability of NPs was significantly enhanced in the presence of NOM. To study this effect, the FT-IR analysis of $\mathrm{ZnO}-\mathrm{NOM}$ complex was performed, which confirmed the presence of carboxylate groups on the surface of NPs. Furthermore, the kinetic study revealed different aggregation behavior and settling rate of NPs under various solution conditions.

The variation in several factors may occur simultaneously in the aquatic environment, thus multiple factors at three levels were considered. The ANOVA result and range analysis of matrix showed that electrolyte concentration and divalent cation content were the most significant factors followed by electrolyte type to enhance the sedimentation, whereas the effect of NOM concentration rather than its type was found to influence the aggregation. The effect of other factors and interactions were found insignificant. Therefore, $\mathrm{ZnO}$ NPs may behave differently when interacting with co-varying pertinent factors in the same system. Finally, the applicability of this approach was confirmed on 
various environmental water samples. Future research and endeavors shall focus on more complex and environmentally relevant conditions to evaluate the fate and transport of other ENPs in an aquatic system, which ultimately have an impact on uptake and therefore bioavailability and toxicity of ENPs to humans and eco-system.

Supplementary Materials: The following are available online at http:/ / www.mdpi.com/2073-4441/10/5/660/ s1, Table S1: Summary of physicochemical properties of ZnO NPs; Table S2: Natural and synthetic water characteristics; Table S3: Settling velocity and viscosity of ZnO NPs suspension at various water temperature; Figure S1: (A) UV-Vis spectra of ZnO NP $(100 \mathrm{mg} / \mathrm{L})$ in pure water by full-wave scanning; (B) Standard calibration curve of ZnO NPs concentration; Figure S2: (A)Effect of ultrasonic time (5-40 min) and ultrasonic power $(100-600 \mathrm{~W})$ on suspension stability of ZnO NPs (100 mg/L); (B) Zeta potential of ZnO NPs suspension (mean $\pm \mathrm{SD}, n=3)$ at different $\mathrm{pH}$; (C) FTIR spectrum of ZnO NPs; Figure S3: Fit of the sedimentation data to Stokes equation. Exponential model for $100 \mathrm{mg} / \mathrm{L}, 50 \mathrm{~nm} \mathrm{ZnO}$ NPs at $\mathrm{pH} 9$ in pure water.

Author Contributions: R.K. and I.T.Y. designed the study; R.K., M.A.I., S.Z.Z. and D.R.P. performed the experiment and analyzed the data, and R.K. wrote the article.

Acknowledgments: This research did not receive any grant from funding agency in the public, commercial, or not-for-profit sectors.

Conflicts of Interest: The authors declare no conflicts of interest.

\section{References}

1. Keller, A.A.; McFerran, S.; Lazareva, A.; Suh, S. Global life cycle releases of engineered nanomaterials. J. Nanopart. Res. 2013, 15, 1692. [CrossRef]

2. Handy, R.D.; Von Der Kammer, F.; Lead, J.R.; Hassellöv, M.; Owen, R.; Crane, M. The ecotoxicology and chemistry of manufactured nanoparticles. Ecotoxicology 2008, 17, 287-314. [CrossRef] [PubMed]

3. Brunner, T.J.; Wick, P.; Manser, P.; Spohn, P.; Grass, R.N.; Limbach, L.K.; Bruinink, A.; Stark, W.J. In vitro cytotoxicity of oxide nanoparticles: Comparison to asbestos, silica, and the effect of particle solubility. Environ. Sci. Technol. 2006, 40, 4374-4381. [CrossRef] [PubMed]

4. Xia, T.; Kovochich, M.; Liong, M.; Mädler, L.; Gilbert, B.; Shi, H.; Yeh, J.I.; Zink, J.I.; Nel, A.E. Comparison of the Mechanism of toxicity of Zinc and Cerium Oxide Nanoparticles Based on Dissolution and Oxidative Stress Properties. Am. Chem. Soc. Nano 2008, 2, 2121-2134. [CrossRef] [PubMed]

5. Lin, D.; Xing, B. Root Uptake and Phytotoxicity of ZnO Nanoparticles. Environ. Sci. Technol. 2008, 42, 5580-5585. [CrossRef] [PubMed]

6. Miao, A.J.; Zhang, X.Y.; Luo, Z.; Chen, C.S.; Chin, W.C.; Santschi, P.H.; Quigg, A. Zinc oxide-engineered nanoparticles: Dissolution and toxicity to marine phytoplankton. Environ. Toxicol. Chem. 2010, 29, 2814-2822. [CrossRef] [PubMed]

7. Dhas, S.P.; Shiny, P.J.; Khan, S.; Mukherjee, A.; Chandrasekaran, N. Toxic behavior of silver and zinc oxide nanoparticles on environmental microorganisms. J. Basic Microbiol. 2014, 54, 916-927. [CrossRef] [PubMed]

8. Zhang, S.; Jiang, Y.; Chen, C.S.; Spurgin, J.; Schwehr, K.A.; Quigg, A.; Chin, W.C.; Santschi, P.H. Aggregation, dissolution, and stability of quantum dots in marine environments: Importance of extracellular polymeric substances. Environ. Sci. Technol. 2012, 46, 8764-8772. [CrossRef] [PubMed]

9. He, D.; Bligh, M.W.; Waite, T.D. Effects of aggregate structure on the dissolution kinetics of citrate-stabilized silver nanoparticles. Environ. Sci. Technol. 2013, 47, 9148-9156. [CrossRef] [PubMed]

10. Li, M.; Zhu, L.; Lin, D. Toxicity of ZnO nanoparticles to escherichia Coli: Mechanism and the influence of medium components. Environ. Sci. Technol. 2011, 45, 1977-1983. [CrossRef] [PubMed]

11. Bennett, S.W.; Adeleye, A.; Ji, Z.; Keller, A.A. Stability, metal leaching, photoactivity and toxicity in freshwater systems of commercial single wall carbon nanotubes. Water Res. 2013, 47, 4074-4085. [CrossRef] [PubMed]

12. Quik, J.T.K.; Velzeboer, I.; Wouterse, M.; Koelmans, A.A.; van de Meent, D. Heteroaggregation and sedimentation rates for nanomaterials in natural waters. Water Res. 2014, 48, 269-279. [CrossRef] [PubMed]

13. Degen, A.; Kosec, M. Effect of $\mathrm{pH}$ and impurities on the surface charge of zinc oxide in aqueous solution. J. Eur. Ceram. Soc. 2000, 20, 667-673. [CrossRef]

14. French, R.A.; Jacobson, A.R.; Kim, B.; Isley, S.L.; Penn, R.L.; Baveye, P.C. Influence of ionic strength, pH, andcation valence on aggregation kinetics of titanium dioxide nanoparticles. Environ. Sci. Technol. 2009, 43, 1354-1359. [CrossRef] [PubMed] 
15. Li, X.; Lenhart, J.J.; Walker, H.W. Aggregation kinetics and dissolution of coated silver nanoparticles. Langmuir 2012, 28, 1095-1104. [CrossRef] [PubMed]

16. Odzak, N.; Kistler, D.; Behra, R.; Sigg, L. Dissolution of metal and metal oxide nanoparticles in aqueous media. Environ. Pollut. 2014, 191, 132-138. [CrossRef] [PubMed]

17. Philippe, A.; Schaumann, G.E. Interactions of dissolved organic matter with natural and engineered inorganic colloids: A review. Environ. Sci. Technol. 2014, 48, 8946-8962. [CrossRef] [PubMed]

18. Majedi, S.M.; Kelly, B.C.; Lee, H.K. Combined effects of water temperature and chemistry on the environmental fate and behavior of nanosized zinc oxide. Sci. Total Environ. 2014, 496, 585-593. [CrossRef] [PubMed]

19. Van Hoecke, K.; De Schamphelaere, K.A.C.; Van Der Meeren, P.; Smagghe, G.; Janssen, C.R. Aggregation and ecotoxicity of $\mathrm{CeO}_{2}$ nanoparticles in synthetic and natural waters with variable $\mathrm{pH}$, organic matter concentration and ionic strength. Environ. Pollut. 2011, 159, 970-976. [CrossRef] [PubMed]

20. Romanello, M.B.; Fidalgo de Cortalezzi, M.M. An experimental study on the aggregation of $\mathrm{TiO}_{2}$ nanoparticles under environmentally relevant conditions. Water Res. 2013, 47, 3887-3898. [CrossRef] [PubMed]

21. Peng, C.; Shen, C.; Zheng, S.; Yang, W.; Hu, H.; Liu, J.; Shi, J. Transformation of CuO Nanoparticles in the Aquatic Environment: Influence of pH, Electrolytes and Natural Organic Matter. Nanomaterials 2017, 7, 326. [CrossRef] [PubMed]

22. Guzman, K.A.D.; Finnegan, M.P.; Banfield, J.F. Influence of surface potential on aggregation and transport of Titania nanoparticles. Environ. Sci. Technol. 2006, 40, 7688-7693. [CrossRef] [PubMed]

23. Domingos, R.F.; Tufenkji, N.; Wilkinson, K.J. Aggregation of Titanium Dioxide Nanoparticles: Role of a Fulvic Acid Aggregation of Titanium Dioxide Nanoparticles: Role of a Fulvic Acid. Environ. Sci. Technol. 2009, 43, 1282-1286. [CrossRef] [PubMed]

24. Gondikas, A.P.; Morris, A.; Reinsch, B.C.; Marinakos, S.M.; Lowry, G.V.; Hsu-Kim, H. Cysteine-induced modifications of zero-valent silver nanomaterials: Implications for particle surface chemistry, aggregation, dissolution, and silver speciation. Environ. Sci. Technol. 2012, 46, 7037-7045. [CrossRef] [PubMed]

25. Phadke, M.S. Uauty Engineering Using Robust Design; Prentice Hall: Upper Saddle River, NJ, USA, 1989; ISBN 0137451679.

26. Raj, C.B.C.; Quen, H. Advanced oxidation processes for wastewater treatment: Optimization of $U V / \mathrm{H}_{2} \mathrm{O}_{2}$ process through a statistical technique. Chem. Eng. Sci. 2005, 60, 5305-5311. [CrossRef]

27. Lan, W.G.; Wongt, M.K.; Chen, N.; Sin, Y.M. Orthogonal array design as a chemometric method for the optimization of analytical procedures. Part 5 . Three-level design and its application in microwave dissolution of biological samples. Analyst 1995, 120, 1115-1124. [CrossRef] [PubMed]

28. Zhu, M.; Wang, H.; Keller, A.A.; Wang, T.; Li, F. The effect of humic acid on the aggregation of titanium dioxide nanoparticles under different $\mathrm{pH}$ and ionic strengths. Sci. Total Environ. 2014, 487, 375-380. [CrossRef] [PubMed]

29. Wright, M.R. Introduction to Chemical Kinetics; John Wiley \& Sons: Hoboken, NJ, USA, 2005; ISBN 047002593X.

30. Mudunkotuwa, I.A.; Rupasinghe, T.; Wu, C.-M.; Grassian, V.H. Dissolution of ZnO Nanoparticles at Circumneutral pH: A Study of Size Effects in the Presence and Absence of Citric Acid. Langmuir 2012, 28, 396-403. [CrossRef] [PubMed]

31. Sen, C.D.; Son, J.I.; Kim, H.H.; Yun, H.S.; Cho, N.H. Variation of the nanostructural feature of nc-SiC:H thin films with post-deposition thermal annealing. Thin Solid Films 2014, 571, 238-244. [CrossRef]

32. Peng, Y.H.; Tsai, Y.C.; Hsiung, C.E.; Lin, Y.H.; Shih, Y.H. Influence of water chemistry on the environmental behaviors of commercial $\mathrm{ZnO}$ nanoparticles in various water and wastewater samples. J. Hazard. Mater. 2017, 322, 348-356. [CrossRef] [PubMed]

33. Matrajt, G.; Borg, J.; Raynal, P.I.; Djouadi, Z.; D’Hendecourt, L.; Flynn, G.J.; Deboffle, D. FTIR and Raman analyses of the Tagish Lake meteorite: Relationship with the aliphatic hydrocarbons observed in the Diffuse Interstellar Medium. Astron. Astrophys. 2004, 416, 983-990. [CrossRef]

34. Kumar, H.; Rani, R. Structural and Optical Characterization of ZnO Nanoparticles Synthesized by Microemulsion Route. Int. Lett. Chem. Phys. Astron. 2013, 19, 26-36. [CrossRef]

35. Bian, S.W.; Mudunkotuwa, I.A.; Rupasinghe, T.; Grassian, V.H. Aggregation and dissolution of $4 \mathrm{~nm} \mathrm{ZnO}$ nanoparticles in aqueous environments: Influence of $\mathrm{pH}$, ionic strength, size, and adsorption of humic acid. Langmuir 2011, 27, 6059-6068. [CrossRef] [PubMed] 
36. Baalousha, M. Aggregation and disaggregation of iron oxide nanoparticles: Influence of particle concentration, pH and natural organic matter. Sci. Total Environ. 2009, 407, 2093-2101. [CrossRef] [PubMed]

37. Liu, W.S.; Peng, Y.H.; Shiung, C.E.; Shih, Y.H. The effect of cations on the aggregation of commercial ZnO nanoparticle suspension. J. Nanopart. Res. 2012, 14. [CrossRef]

38. Zhang, Y.; Chen, Y.; Westerhoff, P.; Hristovski, K.; Crittenden, J.C. Stability of commercial metal oxide nanoparticles in water. Water Res. 2008, 42, 2204-2212. [CrossRef] [PubMed]

39. Keller, A.A.; Wang, H.; Zhou, D.; Lenihan, H.S.; Cherr, G.; Cardinale, B.J.; Miller, R.; Zhaoxia, J.I. Stability and aggregation of metal oxide nanoparticles in natural aqueous matrices. Environ. Sci. Technol. 2010, 44, 1962-1967. [CrossRef] [PubMed]

40. Zhang, Y.; Chen, Y.; Westerhoff, P.; Crittenden, J. Impact of natural organic matter and divalent cations on the stability of aqueous nanoparticles. Water Res. 2009, 43, 4249-4257. [CrossRef] [PubMed]

41. Ghosh, S.; Mashayekhi, H.; Bhowmik, P.; Xing, B. Colloidal Stability of $\mathrm{Al}_{2} \mathrm{O}_{3}$ Nanoparticles as Affected by Coating of Structurally Different Humic Acids. Langmuir 2010, 26, 873-879. [CrossRef] [PubMed]

42. Erhayem, M.; Sohn, M. Stability studies for titanium dioxide nanoparticles upon adsorption of Suwannee River humic and fulvic acids and natural organic matter. Sci. Total Environ. 2014, 468-469, 249-257. [CrossRef] [PubMed]

43. Mudunkotuwa, I.A.; Grassian, V.H. Citric Acid Adsorption on $\mathrm{TiO}_{2}$ Nanoparticles in Aqueous Suspensions at Acidic and Circumneutral pH: Surface Coverage, Surface Speciation, and Its Impact on Nanoparticle-Nanoparticle Interactions. J. Am. Chem. Soc. 2010, 132, 14986-14994. [CrossRef] [PubMed]

44. Giasuddin, A.B.M.; Kanel, S.R.; Choi, H. Adsorption of humic acid onto nanoscale zerovalent iron and its effect on arsenic removal. Environ. Sci. Technol. 2007, 41, 2022-2027. [CrossRef] [PubMed]

45. Vlachos, N.; Skopelitis, Y.; Psaroudaki, M.; Konstantinidou, V.; Chatzilazarou, A.; Tegou, E. Applications of Fourier transform-infrared spectroscopy to edible oils. Anal. Chim. Acta 2006, 573-574, 459-465. [CrossRef] [PubMed]

46. Alberts, J.J.; Filip, Z. Metal binding in estuarine humic and fulvic acids: Ftir analysis of humic acid-metal complexes. Environ. Technol. (UK) 1998, 19, 923-931. [CrossRef]

47. Rocchiccioli-Deltcheff, C.; Franck, R.; Cabuil, V.; Massart, R. Surfacted ferrofluids: Interactions at the surfactant-magnetic iron oxide interface. Leuk. Res. 1987, 5, 126-127.

48. Vermeer, A.W.P.; van Riemsdijk, W.H.; Koopal, L.K. Adsorption of Humic Acid to Mineral Particles. 1. Specific and Electrostatic Interactions. Langmuir 1998, 14, 2810-2819. [CrossRef]

49. Huangfu, X.; Jiang, J.; Ma, J.; Liu, Y.; Yang, J. Aggregation kinetics of manganese dioxide colloids in aqueous solution: Influence of humic substances and biomacromolecules. Environ. Sci. Technol. 2013, 47, 10285-10292. [CrossRef] [PubMed]

50. Ohshima, H. The derjaguin-landau-verwey-overbeek (dlvo) theory of colloid stability. In Electrical Phenomena at Interfaces and Biointerfaces Electrical Phenomena at Interfaces and Biointerfaces: Fundamentals and Applications in Nano-, Bio-, and Environmental Sciences, 1; John Wiley \& Sons: Hoboken, NJ, USA, 2012; Volume 27.

(C) 2018 by the authors. Licensee MDPI, Basel, Switzerland. This article is an open access article distributed under the terms and conditions of the Creative Commons Attribution (CC BY) license (http://creativecommons.org/licenses/by/4.0/). 